\title{
Improving Critical Thinking and Metacognition Ability Using Vee Diagram through Problem-Based Learning of Human Respiratory System
}

\author{
Iseu Laelasari \\ Study Program of Biology Education, \\ Universitas Pendidikan Indonesia (UPI) \\ Bandung 40154, Indonesia \\ e-mail: icew90.gadisupi.06@gmail.com
}

\author{
Sri Anggraeni \\ Department of Biology, \\ Universitas Pendidikan Indonesia (UPI) \\ Bandung 40154, Indonesia \\ e-mail: anggraeni_said@yahoo.co.id ${ }^{2}$
}

\begin{abstract}
The aim of this study is to analyse the enhancement student's critical thinking and metacognition after the implementation Vee diagram in Problem Based Learning. This study applies quasi experimental method with matching pretest and posttest control group design. There are $\mathbf{7 4}$ studentsfrom two classes of grade eleven as the participants of this research. Data was collected through essay test (non objective questions)taken frompretest and posttest. Data from pretest and posttest were analyzed using N-gain and Pearson correlation test.Dataanalysisshows that acquisition score $\mathrm{N}$-gain critical thinking and metacognition of experimental group in human respiratory system higher than control group. Indicators of critical thinking on inference, basic support, tactic and strategy of experiment group are at higher category, whereas elementary clarification and advance clarification are at medium category. Metacognition indicators of procedural knowledge, declarative knowledge, conditional knowledge, monitoring comprehension, planning, and evaluation are at high category, and cognition regulation and debugging strategy of experimental class are at medium category. Analysis of Pearson correlation shows that there are strong correlation between critical thinking and metacognition in experimental group, and medium correlation in control group.
\end{abstract}

Keywords - Vee Diagram; Problem Based Learning; Critical thinking; Metacognition; Human Respiratory System.

\section{INTRODUCTION}

PBL (Problem Based Learning) is a development of active learning and student centered learning which uses the unstructured problems as a starting point in the learning process [1]. PBL can be set up or managed the learning through problem-solving activities and gives students the opportunity to develop their critical thinking, posing creative idea, and communicating it to others[2]. Critical thinking skills are very important and necessary in daily life, because someone who has the critical thinking can spare in making decisions or wrong problem solving [3]. Critical thinking is a reasonable thought (based on facts) and reflective (looking for the best possible solutions) that is focused on making the decision on what to do or believe[4]. According to frameworks of Ennis [4], critical thinking consists of 5 indicators, namely: elementary clarification, basic support, inference, advance clarification and tactic and strategy.

Critical thinking skills are related to the person's mental processes or mental activity called as metacognition.
Metacognition includes awareness of thinking about what is known, and this process is important to start learning activities, because students require awareness about their knowledge of what was known and what students want to learn [5]. Metacognition refers to high-level thinking in a cognitive process that it should be actively involved during the learning process [6]. On the other hand, metacognition also provides a way of controlling the thinking that it will ultimately result critical thinking [7]. Metacognition consists of cognitive knowledge (declarative knowledge, procedural knowledge and conditional knowledge) and cognitive regulation (planning, strategy collecting information, monitoring information, debugging strategy and evaluation) [8].

In order to clarify the direction and purpose in learning process, [9] the research offers the use of Vee Diagram, especially for designing lab-based learning. Vee Diagram can help students to understand the concept of learning through meaningful learning activity and improve thinking process, and can be used to help solve problems or understand a procedure. Vee diagram has a conceptual side (think) and methodological side (work) [9]. This chart can give the relationship between theory and practice (thinking and doing), and contains four main sections, namely, a focus question, objects and events, conceptual and methodological side [9][10]. Vee diagram can be used to improve student's metacognition ability [9], and to build aspects of high-level skills in problem solving, to improve understanding about a topic, to help in the assimilation and to accommodate of knowledge constructed by learners. It is useful in the process of thought scaffolding or reasoning of learners and to illustrate their understanding of the interrelationships between theory and application in problem solving [11]. By making Vee Diagram, student can develop an understanding of procedural, relational or conceptual [12].

\section{RESEARCH METHODOLOGY}

This study used an experimental method with quasi experiment and matching pretest-posttest control group design. It's implemented in one senior high school in Bandung, West Java. The sample of this study are consisted of 74 participantsfrom two classes (experiment and control groups) of grade 11 of the academic years2015/2016.The study was implemented during regular class and conducted four 90 minutes period. The instrument used of this study is 
critical thinking and metacognition test. It's consisted of 20 essay questions with the coefficient reliability 0.96 . To acquire an increase students' critical thinking and metacognition, the test was given before and after implementation Vee diagram [9] in Problem Based Learning (PBL) in experimental class and PBL without Vee diagram in control class [13] in learning human respiratory system with the same instrument test. The increasing of critical thinking and metacognition and correlation were analyzed using $\mathrm{N}$-gain and Pearson correlation test.

\section{RESULTS AND DISCUSSION}

From the data obtained, increasing the ability of critical thinking in experimental group indicates of inference, basic support, tactic and strategy at high category while in control group indicates inference, tactic and strategy at medium category [14].It's shown in Table 1.

TABLE I. MEAN N-GAIN CRITICAL THINKING OF EXPERIMENT AND CONTROL GROUP

\begin{tabular}{|l|l|l|l|l|}
\hline \multirow{2}{*}{ Indicator } & \multicolumn{2}{|c|}{ Mean N-Gain } & \multicolumn{2}{c|}{ Standard Deviation } \\
\cline { 2 - 5 } & $\begin{array}{c}\text { Experiment } \\
\text { group }\end{array}$ & $\begin{array}{c}\text { Control } \\
\text { group }\end{array}$ & $\begin{array}{c}\text { Experiment } \\
\text { group }\end{array}$ & $\begin{array}{c}\text { Control } \\
\text { group }\end{array}$ \\
\hline $\begin{array}{l}\text { Elementary } \\
\text { clarification }\end{array}$ & 0.55 & 0.27 & 0.183 & 0.133 \\
\hline $\begin{array}{l}\text { Basic } \\
\text { Support }\end{array}$ & 0.76 & 0.18 & 0.230 & 0.196 \\
\hline Inference & 0.81 & 0.39 & 0.195 & 0.247 \\
\hline $\begin{array}{l}\text { Advance } \\
\text { clarification }\end{array}$ & 0.56 & 0.18 & 0.242 & 0.231 \\
\hline $\begin{array}{l}\text { Tactic and } \\
\text { strategy }\end{array}$ & 0.71 & 0.30 & 0.290 & 0.285 \\
\hline
\end{tabular}

Based on Table 1, the highest increase occurs (N-gain) in inference ability in each group. This means that students who havethe highest increase in making deductions and considering the results of deduction. they make induction and consider the results of induction and making decisions and assessing the results [4]. This happens because at syntax of PBL students are trained to explore the result of investigation about the problem, and students should make their conclusions correspond with those problems[13][15]. These results prove the opinion [16]that critical thinking skills can be enhanced through problem-solving activity. They canformulate the factors that affect, calculate the various possibilities and make a decision.

The application of Vee diagram in the learning process of experiment class, further enhances critical thinking skills than in the control class. Vee diagram has several components such as focusing on question aspects, objects and events that can connect the conceptual and methodological aspects [9]These aspects are also very potential to develop reasoning ability and build knowledge [12].

In learning process by applying Vee diagram, students are trained to be able to collect and build information (basic support) on a problem that has been formulated especifically through a focus question, so that students can collect information (data) which are more focused through objects and events that they have set. In addition, the implementation of Vee diagram in PBL is more accustomed to students in choosing and determining the strategy and selecting steps link to the focus question. They can collect data from objects and events. Students are also trained to be able to build their conceptual knowledge in the form of knowledge claim of the data they have collected through the steps or particular procedure, so that students are trained to make the suitable inference (knowledge claim) with focus question. These results are in accordance to the opinion [12] that through the construction Vee diagram, learners will achieve competence deeper and more proficient in using the methods for problem solving.

From the data obtained, increasing the ability of metacognition in experimental group the indicator of procedural knowledge, declarative, conditional, monitoring comprehension, planning and evaluation are at high category whereas in control group, declarative knowledge, planning and strategy of collect information are at medium category [14]. It's shown in Table 2.

TABLE II. MEAN N-GAIN METACOGNITION OF EXPERIMENT AND CONTROL GROUP

\begin{tabular}{|l|l|l|l|c|}
\hline \multirow{2}{*}{ Indicator } & \multicolumn{2}{|c|}{ Mean N-Gain } & \multicolumn{2}{c|}{ Standard Deviation } \\
\cline { 2 - 5 } & $\begin{array}{c}\text { Experiment } \\
\text { group }\end{array}$ & $\begin{array}{c}\text { Control } \\
\text { group }\end{array}$ & $\begin{array}{c}\text { Experiment } \\
\text { group }\end{array}$ & $\begin{array}{c}\text { Control } \\
\text { group }\end{array}$ \\
\hline $\begin{array}{l}\text { Declarative } \\
\text { knowledge }\end{array}$ & 0.88 & 0.42 & 0.298 & 0.388 \\
\hline $\begin{array}{l}\text { Procedural } \\
\text { knowledge }\end{array}$ & 0.98 & 0.00 & 0.082 & 0.000 \\
\hline $\begin{array}{l}\text { Conditional } \\
\text { knowledge }\end{array}$ & 0.81 & 0.11 & 0.263 & 0.179 \\
\hline Planning & 0.74 & 0.37 & 0.418 & 0.399 \\
\hline $\begin{array}{l}\text { Strategy collecting } \\
\text { information }\end{array}$ & 0.35 & 0.36 & 0.483 & 0.452 \\
\hline $\begin{array}{l}\text { Monitoring } \\
\text { comprehension }\end{array}$ & 0.79 & 0.26 & 0.381 & 0.345 \\
\hline Debugging strategy & 0.68 & 0.22 & 0.315 & 0.299 \\
\hline Evaluation & 0.74 & 0.23 & 0.363 & 0.369 \\
\hline
\end{tabular}

The difference mean of $\mathrm{N}$-gain metacognition between experiment and control group prove that Vee diagrams can be used to build high-level skills (including metacognition) to solve the problem [6][11].These results are also supported by the opinion [9] that Vee diagrams can be used to build students' metacognition abilities. According table 2 , indicators of procedural knowledge, declarative knowledge, conditional knowledge, monitoring comprehension, planning and evaluation show the highest $\mathrm{N}$-gain (N-gain: 0.98, 0.88, $0.81,0.79,0.74$ and 0.74$)$. In fact that the learning process on the following pattern of Vee diagrams, students are trained to be able to record data or information obtained from object and event.They are more organized, then they interpret it into other form for making it easier to read. This record and interpreted data are used to construct the conceptual aspects through several questions posed by the teacher. In addition, students are trained to select the specific procedures which are the most suitable in order to answer the focus question. Through the pattern of Vee diagram, students are trained for monitoring their comprehension about concept, procedures, and evaluation.

These results are also suitable with the opinion [11] that by creating a Vee diagram, learners can develop their conceptual and procedural comprehension. Vee diagrams also help the process of assimilation and accommodation. Moreover it is useful in reasoning scaffolding of learners and illustrating their understanding of the relationship between theory and application in problem solving [12]. 


\section{References}

correlation.it shows there are strong correlation between critical thinking and metacognition in experiment class and it shows medium correlation in control group. The result shown in table 3.

TABLE III. CORRELATION BETWEEN CRITICAL THINKING AND METACOGNITION OF EXPERIMENT AND CONTROL GROUP

\begin{tabular}{|c|c|c|c|}
\hline Group & $\mathbf{N}$ & Pearson correlation & Sig (1-tailed) \\
\hline Experiment & 37 & 0.652 & 0.000 \\
\hline Control & 37 & 0.516 & 0.001 \\
\hline
\end{tabular}

According table 3, student's critical thinking and metacognition in the experimental class and control class shows positive correlation. It can be seen from the value of the correlation among both parties. The result of Pearson test indicates that there are strong correlation between the critical thinking and metacognition in experimental class $(r=0652)$ and medium correlation in control class $(r=0.516)$. These results are consistent with research conducted by [17] which shows that student with good critical thinking also has good metacognition ability. This is supported by the opinion [18] that students who have good metacognitive development will be better insolving problems, making decisions and critical thinking.

\section{CONCLUSION}

Based on analyzing result and discussion, it can be drawn a conclusion that the application of Vee diagram in PBL increases students' critical thinking and metacognition better than PBL without Vee diagram in learning human respiratory system. Critical thinking indicators of inference, basic support, tactic and strategy of experiment group have increased significantly by $0.81,0.76$ and 0.71 . Metacognition indicators of procedural knowledge, declarative knowledge, conditional knowledge, monitoring comprehension, planning, and evaluation of experiment group have increased by $0.98,0.88$, $0.81,0.79,0.74$ and 0.74 consecutively. There are strong correlation between critical thinking and metacognition in experiment class $(\mathrm{r}=0.652)$ and medium correlation in control group $(r=0.516)$.

\section{Acknowledgment}

The authors are very gratefully of acknowledge the input of those academic, technical and support staff from the College of Biology Education, Universitas Pendidikan Indonesia, especially to Prof. Dr. Fransisca Sudargo, M.Pd., Dr. Bambang Supriatno, M.Si., and Dr. Siti Sriyati, M.Si., as validators of instrument used in this research. The authors also thank so much to all stakeholders of SMA Negeri 3 Bandung, especially to H. Encang Iskandar, M.Pd., Taman Sutarman, S.Pd., Dra. Nenden Komara, and Rizky Adi Pranyoto, A.Md., for helping us in completing the research and data collecting. 